\title{
A Review of Occupant-Centric Building Control Strategies to Reduce Building Energy Use
}

Sophie Naylor*a, Mark Gillott ${ }^{\mathrm{a}}$, Tom Lau ${ }^{\mathrm{b}}$

${ }^{a}$ Department of Architecture and Built Environment, Faculty of Engineering, University of Nottingham, UK.

${ }^{\mathrm{b}}$ Engineering Excellence Group, Laing O'Rourke, UK.

*Corresponding author. Email: sophie.naylor@ nottingham.ac.uk Tel: +44-1158467677 


\begin{abstract}
Building Energy Management is identified as a key part of the move towards localised energy generation and control. The significant discrepancy between building energy use as designed and during actual operation shows a need to evaluate the relationship between building occupants and energy requirements. The need to better account for the influence of occupants on building energy use has been established through post-occupancy studies, highlighting the characteristics needed for more successful building control systems. This paper provides an overview of current building control systems technology and discusses existing academic research into more advanced occupant-centric controls. The potential for application of various methods is compared. It is found that study into occupant-centred control systems covers a wide array of approaches, ranging from simple presence-based switching of lighting systems to full model predictive control. Studies suggest an optimum point balancing the complexity of a system against its potential for saving energy.
\end{abstract}

\title{
Keywords
}

Building Automation, Building Energy Management, Occupancy 


\section{Introduction}

As energy generation for buildings becomes increasingly localised thanks to advances in renewable technologies, the mismatch between real-time energy generation and use leads to a need for effective localised energy control. The use of Building Energy Management Systems (BEMS) to cater building energy use directly to occupant needs has an important role to play in this system. This paper seeks to provide a review of approaches to energy management that place specific emphasis on collecting and reacting to real-time occupant data. This work builds upon the detailed review of the impacts of occupancy on energy and current capability of Building Energy Management solutions established in [1], with an emphasis on the methods and hardware used to accurately detect occupant data and a broader review on how this data is implemented intro building control. Through cross-review of the existing body of work in these fields, this study aims to highlight current issues/complicating factors in occupancy detection, emerging techniques/technologies and potential routes to improving the robust performance of occupant-centric building controls.

Data collected during building operation typically shows a significant difference between designed and actual energy use in buildings across multiple sectors, as shown in Figure 1-1. Discrepancies between predicted and real building performance are caused by: underestimation of predicted values for reasonable building use during the design phase, potential construction defects causing deviation from the designed build quality, and excessively wasteful use of resources during actual operation. Both the design and operational issues are affected by the "inability of current modelling methods to represent realistic use and operation of buildings" [2]. Menezes et al. highlight the fact that occupant behaviour is one of the major factors contributing to excessive energy use during building operation, alongside effectiveness of services control and deviations from designed build quality.

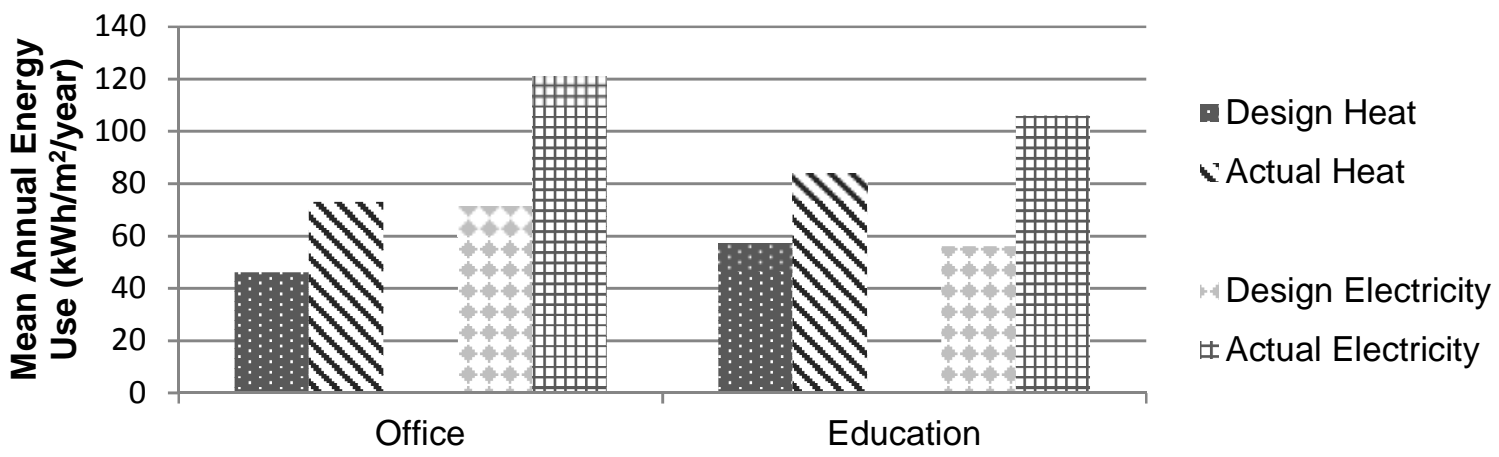

Figure 1-1 - Predicted Versus Actual Energy Use in Commercial Buildings [3]

The contribution of occupancy/occupant behaviours towards final energy use in buildings has been assessed in several studies. Simulation of different schedules and behaviours within commercial buildings has shown an occupant-dependent variation of from $30 \%$ [4] to $150 \%$ [5] of final energy use. Studies of control systems and real buildings have shown high variation in domestic electrical loads depending on occupant behaviours [6,7]. In commercial buildings, it was found that building services have poor response to occupant presence patterns [8], noting that energy used on HVAC was sometimes higher in unoccupied spaces than occupied [9]. This suggests the need for more occupancy-centric control systems.

Most research looking specifically at behavioural impact on building energy use shows that there is significant potential for energy saving through greater understanding of building use. 
The field of detailed exploration into occupant behaviour is relatively young, meaning that there is currently a lack of large-scale in-use data for buildings in the UK [10].

\section{Energy Management Systems - Current state}

As it has been seen that occupancy and occupant behaviours can significantly affect the way a building operates, it must be addressed whether current building control systems are operated sensitively in response to changing occupant needs. The automated control of buildings encompasses an array of different technologies and is described using many different terms. In this publication, the term Building Energy Management Systems (BEMS) is used.

\subsection{Commercially available technology}

Application of BEMS is highly variable in both commercial and domestic buildings. The general structure of BEMS can be defined as: a centralised management layer where general policies and decision making is applied, a field layer of local devices to measure and actuate changes to the indoor environment, and an automation layer interfacing between the two with localised controllers [11].

The area of energy and comfort management in buildings has received significant research interest over the last decade [12]. Despite this interest, an estimated $90 \%$ of current HVAC control systems do not run optimally [13], showing the need for an improvement in the way that controls are designed and implemented. Commercial systems tend to rely on pre-set working schedules, based on the occupancy patterns estimated at the building design stage. It has been found that such schedules can differ dramatically from actual use patterns, causing energy waste [14].

The last few years have seen a dramatic rise in commercial interest in energy management software and hardware, typically procured as a retrofit to existing or recently completed buildings. Often the retrofitted solution can only control the building's energy consumption so far as the existing sensing/actuation system allows; requiring the major overhaul of a full BEMS and significant physical changes for more comprehensive control. Due to increasingly cheap hardware including wireless sensors/actuators, and the availability of configurable software, the barriers to entry for more sophisticated energy management solutions have lowered in recent years.

Commercial reports hint towards the importance of the software intelligence and data analysis side of the BEMS business in the near future [15]. In the domestic field in particular, recent years have seen a large increase in the sophistication of occupancy-related tools in energy management: Table 2-1 summarises the capability of popular 'smart' domestic heating control systems. It can be seen that many major controllers are adopting learning algorithms and occupancy-responsive technology, facilitated by the wider availability of easily installed wireless sensors etc. Trends towards occupant-responsive systems and integration with personal devices for remote control can also be seen in popular home automation management hubs and software. These 'central hub' solutions typically offer a more open system compatible with third party hardware using multiple communication protocols [16]. 
Table 2-1 - Comparison of major domestic heating controls packages available in the UK as of Q4 2017

\begin{tabular}{|c|c|c|c|c|c|}
\hline & $\begin{array}{c}\text { Hive Active } \\
\text { Heating } 2 \text { (2016) } \\
{[17]}\end{array}$ & $\begin{array}{l}\text { Nest v3 (UK) } \\
(\mathbf{2 0 1 7})[18]\end{array}$ & $\begin{array}{c}\text { Heat Genius (2016) } \\
{[19]}\end{array}$ & Tado (2016) [20] & $\begin{array}{c}\text { Honeywell } \\
\text { Evohome (2015) } \\
{[21]}\end{array}$ \\
\hline Multi-zone control & $\begin{array}{l}\text { Up to } 3 \text { zones if } \\
\text { boiler allows }\end{array}$ & $\begin{array}{l}\text { Per thermostat if } \\
\text { boiler allows }\end{array}$ & $\bullet$ & Per thermostat & $\bullet$ \\
\hline Remote Control & $\bullet$ & $\bullet$ & $\diamond$ & $\bullet$ & $\bullet$ \\
\hline $\begin{array}{l}\text { User Motion } \\
\text { Sensing }\end{array}$ & & $\bullet$ & $\bullet$ & & \\
\hline User Geolocation & $\begin{array}{l}\text { Limited - prompts } \\
\text { manual alterations }\end{array}$ & $\bullet$ & & $\bullet$ & \\
\hline $\begin{array}{l}\text { Learning heat } \\
\text { response }\end{array}$ & & $\bullet$ & $\bullet$ & $\bullet$ & $\bullet$ \\
\hline Weather data use & & $\diamond$ & $\diamond$ & $\bullet$ & \\
\hline $\begin{array}{l}\text { Additional } \\
\text { features }\end{array}$ & $\begin{array}{l}\text { - Security } \\
\text { Integration }\end{array}$ & $\begin{array}{l}\text { - Self-learning } \\
\text { schedules* } \\
\text { - Security } \\
\text { Integration }\end{array}$ & $\begin{array}{l}\text { - Modular } \\
\text { - Further home } \\
\text { automation }\end{array}$ & $\begin{array}{l}\text { - Distance } \\
\text { dependent } \\
\text { temperature } \\
\text { setback }\end{array}$ & $\begin{array}{l}\text { - High control } \\
\text { granularity }\end{array}$ \\
\hline
\end{tabular}

The greater sophistication of domestic systems can be difficult to apply to larger, more complex commercial systems, where a high number of occupants may cohabit in a space and obtaining occupancy/behavioural data becomes more complex.

\section{Collection of Occupant Data}

The concept of 'occupant data' is not standardised, meaning that occupant-centric controls can be operated from a widely varied range of collected data, each with its own characteristics [23]. In this publication, 'occupancy' refers to the presence or number of people in a space. 'Location' refers to the localisation of occupants within a space, and 'Occupant behaviour' refers to a higher level of inference based on occupant interactions with the building.

\subsection{Occupant Presence/Number}

The binary parameter of whether or not any occupants are present in a space is one of the simplest forms of occupancy sensing, but is still difficult to achieve $100 \%$ accuracy with current technology. Generally, a reasonable accuracy can be achieved by installing motion/PIR sensors [24], particularly in small spaces with only one occupant [25]. Estimation of the number of people in a space is considerably more complicated than presence alone. Research in the field has explored a wide range of possible methods, each with its own benefits and drawbacks.

The use of a single sensor type to count occupants is attractive due to its lower complexity and installation costs. $\mathrm{CO}_{2}$ concentration sensors are commonly used, but have a delayed response time as $\mathrm{CO}_{2}$ exhaled by occupants takes time to accumulate to elevated levels [23]. Visual methods using the feed from cameras [26] [27] are computationally intensive and depend heavily on lighting conditions and space arrangement for their accuracy.

A popular method in recent research is the combination of data from several different sensor types. This has the benefit of being able to use non-intrusive, relatively inexpensive sensors and generally achieves higher accuracy than using only a single sensor type. Common sensors included are PIR and $\mathrm{CO}_{2}$, which were used alongside cameras [26], ventilation 
actuator signals [28], relative humidity, acoustic and temperature sensors [29-32]. In analysis of the information gained by each new sensor type, Lam et al. found that the most useful sensors in an open-plan office space were relative humidity, acoustic, $\mathrm{CO}_{2}$ and temperature sensors [30] while a systematic approach applied by Ekwevugbe et al. favoured $\mathrm{CO}_{2}$ trend, computer use and acoustic levels [32]. One consideration that arises from comparing multisensor studies is the relative performance of sensor types in different applications: where sensors rely on physical properties of a space, the quality of occupancy information provided can vary significantly between different building layouts, space uses etc. This remains a drawback to generic application of ambient environmental sensing systems.

\subsection{Location Sensing}

Location information about building occupants provides a platform for much richer analysis of occupant impacts on building energy use and the possibility of tailoring building control to an individual level. However, this increased detail of collected information often causes more concerns about privacy and typically requires the specific permission of building occupants before implementation.

Wearable radio-frequency tags are a common occupant location technology, used to transmit location signals to receivers around the sensed space [33-35]. When used alone, tagging systems can have issues with calibration and reflected signals adding noise to the receiver input. It can also be more difficult to detect moving occupants than stationary [35]. The use of many receivers around a space [36-38] or using tags in tandem with infrared detectors [39] can significantly improve the accuracy of location. While fine-grained data is obtainable through this method, tagging of occupants is only truly applicable to a space where all occupants are known and can be expected to wear a tag - typically places of work.

Ambient sensing can be used to locate occupants in spaces where occupants are not always known regular visitors, such as in public and retail buildings. For example, the interaction between the human body and ambient wireless LAN signals can be detected and used to infer the location of a person [23], or a dense network of ambient PIR sensors can be used alongside existing $\mathrm{CO}_{2}$ and humidity data to infer location [40]. Methods such as these are often heavy on computation and may be too slow to run in real-time [40].

As uptake of the smartphone and other smart devices has become more common in recent years, a significant amount of research interest has been put into using personal devices for indoor location [34]. There are several possible sources of data that could be used to calculate a user's position:

- Telephone company data/GPS - company data gives a highly coarse approximation to location by using a mobile phone's connection to nearby telephone masts, while GPS can offer more detail when enabled on a device. Both methods suffer accuracy issues when used indoors [41].

- Wi-Fi connection - locally distributed Wi-Fi beacons can be used to locate a smart device by requesting connections, or the ID of a device's current connected Wi-Fi network can be logged over time [42]. However, many smart device users turn off Wi-Fi when not in use, due to the high power drain caused by leaving it on [41].

- Bluetooth - inquiries by Bluetooth beacons can be a slow process, but it has been shown that speed can be improved by locating devices by which can connect to each other [41] 
- Orientation data - the on-board accelerometer and gyroscope found on many smart devices effectively records a user's path through a space, if their starting point is known. Systems have been developed by combining this data with inter-device connections [43] and visual data processing [44].

\subsection{Activity and Energy Behaviours}

It is often an advantage to know the specific activity taking place in an indoor space. This information can be used for user feedback on energy behaviours (e.g. use of appliances, opening/closing windows), analysis of the energy impact of user actions or provide building services control specific to the task's requirements.

A basic approach to learning occupant behavioural context is to highlight recurring patterns in sensor data, which can then be manually assigned to activity types [45]. Along similar lines, entrance/exit people-counting sensors can be used to identify anomalous events in occupancy and their time span, as these events have the greatest impact on the effectiveness of scheduling in building control systems [46]. This approach has limited scope for wider application due to the need for manual labelling of activities, but presents the first step towards learning behaviour in buildings.

Automated detection of activity types can be achieved by including more detail in the sensed variables. For example, measurements from a range of ambient sensors including motion sensors, sound level and chair pressure pads have been shown to detect office activities with high accuracy [47]. Other approaches include the measurement of when appliances and objects are used [48-51], assuming that most human activities involve interaction with some measurable object. A typical problem with this approach is that all expected activities must be predefined and sensors specified for each object interaction. Activities not originally considered will not be detected at all. However, in applications that require actions targeted only at specific circumstances, this limitation is not an issue. For example, systems to identify unusual or low activity levels in assisted living spaces have been developed to identify when an occupant may need medical help [52]. It should also be noted that, as with other multisensor ambient detection systems, the accuracy of a trained activity model using similar data sources can vary dramatically in spaces occupied by different people, suggesting that generic application of the same system may not be feasible [49].

Analysis of camera feeds may provide a more generic solution, but requires an extremely high amount of processing and current research cannot produce consistently accurate results [53]. As with any use of processed visual data, there are also issues with privacy that prevent widespread application.

\subsection{Discussion}

With advances in the scope and availability of various sensing devices in recent years [54], there has been a significant increase in the amount of study into occupant data in the built environment. Many studies focus on improving sensing technology itself, through studying the most effective combinations of sensors or applying new techniques to allow more effective inference of occupancy rates. The use of trained machine learning models to combine sensor data is widespread, although some studies have opted for systems that do not require manually labelled training data. Much of the work discussed is in its early developmental stages and can be expected to improve in future applications. Table 3-1 
summarises the main uses, benefits and drawbacks of the various physical sensors used to detect building occupancy.

Some overarching trends can be observed throughout the studies discussed. In particular, it can be seen that the success of occupancy-sensing technologies can be highly dependent on its specific application: from physical characteristics of the space to varying behavioural habits of its occupants. Where designers of building control systems wish to apply a similar system to a range of buildings, this presents a potential issue in providing consistent levels of improvement. This issue is found especially in systems using ambient environmental sensors that rely more strongly on their surrounding physical context.

In many applications, the amount of additional hardware required to collect high quality occupant data may be prohibitively high. For this issue, the possibility of leveraging the widely available hardware of personal devices such as smartphones is an attractive solution. Given the increasingly widespread use of smart devices, this approach appears to show promise for wider future application. However, it should be noted that solutions relying only on personal device data can be skewed towards certain population demographics: a 2017 UK survey suggested that $92 \%$ of 16-19 year olds owned smartphones, in contrast with only $65 \%$ of those aged 65-75 [55].

When selecting which technologies are most appropriate for an application, a balance between the intrusiveness and accuracy of measurement must be decided. Generally, both the level of detail available and its accuracy increases with the inclusion of more sensors and is highest with the more intrusive options, such as wireless tagging of occupants. Different methods also require different levels of processing and training: combining passive ambient sensors is less intrusive and can achieve accurate results, but typically requires extensive manually labelled training data that may not be appropriate for many applications.

The greater the complexity of occupancy information sensed, the lower the accuracy to be expected. The following section discusses applied examples of occupancy sensing, with further justification of the balance between accuracy and detail.

Table 3-1 - A summary of sensors used in occupancy detection and their uses

\begin{tabular}{|c|c|c|c|}
\hline Technology & Strengths & Weaknesses & Ideal Applications \\
\hline $\begin{array}{l}\text { Passive Infrared (PIR)/ Motion } \\
\text { sensors } \\
{[23,24,26,28-32,40,45,56,57]}\end{array}$ & $\begin{array}{ll}- & \text { Relatively low cost } \\
\text { - } & \text { Readily available } \\
\text { - } & \text { Less intrusive }\end{array}$ & $\begin{array}{ll}- & \text { No counting capability } \\
\text { - } & \text { False negatives when } \\
\text { occupants are still } \\
\text { - } \quad \text { Require direct line of sight }\end{array}$ & $\begin{array}{ll}\text { - } & \text { Single-person } \\
\text { offices } \\
\text { - } \quad \text { Individual } \\
\text { cubicles }\end{array}$ \\
\hline $\mathrm{CO}_{2}[23,24,26,28-32,40,56]$ & $\begin{array}{ll}\text { - } & \text { Readily available } \\
\text { - } & \text { Non-intrusive }\end{array}$ & $\begin{array}{ll}\text { - } & \text { Slow response time } \\
\text { - } & \text { Affected by ventilation }\end{array}$ & $\begin{array}{l}\text { - } \quad \begin{array}{l}\text { Smaller volume, } \\
\text { enclosed spaces }\end{array} \\
\text { Known activity } \\
\text { level }\end{array}$ \\
\hline $\begin{array}{l}\text { Volatile Organic Compounds } \\
\text { VOC [56] }\end{array}$ & 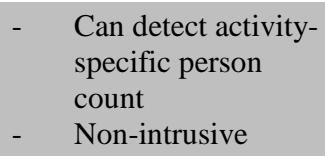 & Very specific application & Kitchen areas \\
\hline Smart meter data mining [58] & $\begin{array}{cc}\text { - Uses existing } \\
\text { infrastructure } \\
\text { - } \quad \text { Non-intrusive }\end{array}$ & $\begin{array}{l}\text { - False negatives when } \\
\text { occupants are not using } \\
\text { electricity }\end{array}$ & Residential \\
\hline Illuminance $[24,31]$ & $\begin{array}{ll}\text { - } & \text { Relatively low cost } \\
\text { - } & \text { Readily available } \\
\text { - } & \text { Non-intrusive }\end{array}$ & $\begin{array}{l}\text { - Must be combined with } \\
\text { other sensors }\end{array}$ & $\begin{array}{l}\text { - Ambient sensor } \\
\text { combination }\end{array}$ \\
\hline
\end{tabular}




\begin{tabular}{|c|c|c|c|}
\hline Acoustic $[24,29-32]$ & $\begin{array}{ll}- & \text { Relatively low cost } \\
\text { - } & \text { Readily available } \\
\text { - } & \text { Less intrusive }\end{array}$ & $\begin{array}{l}\text { Must be combined with } \\
\text { other sensors }\end{array}$ & $\begin{array}{l}\text { Ambient sensor } \\
\text { combination }\end{array}$ \\
\hline $\begin{array}{l}\text { Appliance/lighting use }[24,32,48- \\
51,56]\end{array}$ & Non-intrusive & $\begin{array}{l}\text { Misses occupants/ } \\
\text { activities not using } \\
\text { electricity }\end{array}$ & $\begin{array}{ll}\text { - } & \text { Ambient sensor } \\
\text { combination } \\
\text { - } & \text { Workplace } \\
\text { activity sensing }\end{array}$ \\
\hline Temperature [29-31,59] & $\begin{array}{ll}\text { - } & \text { Relatively low cost } \\
\text { - } & \text { Readily available } \\
\text { - } & \text { Non-intrusive }\end{array}$ & $\begin{array}{l}\text { - Must be combined with } \\
\text { other sensors }\end{array}$ & $\begin{array}{l}\text { - Ambient sensor } \\
\text { combination }\end{array}$ \\
\hline Door Open/Close Status [57] & Non-intrusive & $\begin{array}{l}\text { - Must be combined with } \\
\text { other sensors }\end{array}$ & $\begin{array}{l}\text { Ambient sensor } \\
\text { combination }\end{array}$ \\
\hline Door Counter [46] & Non-intrusive & $\begin{array}{l}\text { - Can be skewed by multiple } \\
\text { people at once }\end{array}$ & $\begin{array}{ll}\text { - } & \text { Public spaces } \\
\text { - } & \text { Workplaces }\end{array}$ \\
\hline Humidity $[31,40]$ & $\begin{array}{ll}\text { - } & \text { Low cost } \\
\text { - } & \text { Readily available } \\
\text { - } & \text { Non-intrusive }\end{array}$ & $\begin{array}{l}\text { - Must be combined with } \\
\text { other sensors }\end{array}$ & $\begin{array}{l}\text { Ambient sensor } \\
\text { combination }\end{array}$ \\
\hline Cameras $[26,27,44,53]$ & $\begin{array}{l}\text { High level detail } \\
\text { possible }\end{array}$ & $\begin{array}{ll}\text { - } & \text { Privacy concerns } \\
\text { - } & \text { Heavy processing required }\end{array}$ & $\begin{array}{l}\text { Workplaces, } \\
\text { public places } \\
\text { with existing } \\
\text { CCTV }\end{array}$ \\
\hline Radio Frequency tags [35-39] & $\begin{array}{l}\text { High level detail } \\
\text { possible }\end{array}$ & $\begin{array}{ll}\text { - } & \text { Privacy concerns } \\
\text { - } & \text { Hardware must be carried }\end{array}$ & Workplaces \\
\hline Pressure Pads $[42,47,49,52]$ & $\begin{array}{l}\text { Can monitor } \\
\text { specific location } \\
\text { of interest }\end{array}$ & $\begin{array}{ll}- & \text { Privacy concerns } \\
\text { - } & \text { Intrusive installation }\end{array}$ & $\begin{array}{l}\text { Assisted } \\
\text { living, } \\
\text { domestic, } \\
\text { office }\end{array}$ \\
\hline HVAC Actuation & $\begin{array}{l}\text { Helps to account for } \\
\text { ventilation effects }\end{array}$ & $\begin{array}{l}\text { Relationship to occupancy } \\
\text { can be indirect }\end{array}$ & $\begin{array}{ll}\text { - } & \text { Workplaces } \\
\text { - } & \text { Existing HVAC } \\
\text { systems }\end{array}$ \\
\hline Air pressure change [60] & $\begin{array}{ll}- & \text { Non-intrusive } \\
- & \text { Can sense } \\
\text { movement between } \\
\text { spaces }\end{array}$ & $\begin{array}{l}\text { - Relationship to occupancy } \\
\text { can be indirect }\end{array}$ & $\begin{array}{ll}\text { - } & \text { Low occupancy } \\
\text { spaces } \\
\text { - } & \text { Residential }\end{array}$ \\
\hline Smart device tracking [41-44] & $\begin{array}{l}\text { - High level detail } \\
\text { possible }\end{array}$ & $\begin{array}{ll}\text { - } & \text { Privacy concerns } \\
\text { - } & \text { Hardware must be carried } \\
\text { - } & \text { Assumes all occupants } \\
& \text { have a device }\end{array}$ & $\begin{array}{ll}\text { - } & \text { Workplaces } \\
\text { - } & \text { Residential }\end{array}$ \\
\hline
\end{tabular}

\section{Academic Research into Occupant-Centric Controls}

The improvement of occupant-centric control in BEMS has also been subject to an increasing level of academic interest in recent years. Studies have addressed a range of techniques and complexity levels. The mechanism of response to occupant data can also be highly varied. Following the convention established in existing reviews [61], occupant-centric controls have been separated here into four broad categories: reactive response to occupancy in real-time, control to individual occupant preference, control catered to individual behaviours or activities and control based on the prediction of future occupancy/behaviours. It should be noted that these categories are not mutually exclusive: several of the following studies use multiple techniques for building control. 


\subsection{Real-Time Response to Occupancy}

The use of real-time response/reaction to building occupancy is well established in commercial lighting control, with widespread use of PIR motion sensors to switch on/off lighting. In the typical commercial system, lighting is switched on when motion is detected, and switched off after a fixed time delay after the last motion event detected. While some degree of improvement to current lighting control can be offered by optimising time delay after occupancy detection [62], in open-plan spaces techniques to localise lighting only where occupants are present may provide a greater impact [63,64]. Application of occupant data to the control of other more energy-intensive systems has further potential for improvement against current standards. In the domestic sector, products for occupancy-based appliance power management are available [65], but commercial applications in multi-occupancy spaces remain more complex. In application to electrical appliance control, some studies have focussed on local motion sensing to detect presence close to appliances [66], while others have used wearable Bluetooth tags to allow equipment reboot as owners approach [67]. Here, it was concluded that a more detailed situational context was required for reliable appliance control.

The control of building HVAC systems through BEMS is a rapidly developing field. Most occupant-centric research focuses on commercial applications, making use of the prevalence of existing commercial building sensing and automation hardware. Meyer and Rakotonirainy provided an overview of context-aware home projects and their differences to commercial applications [68]. In particular it was noted that commercial and home applications of automation have different sets of priorities, with homes catered to comfort while commercial systems focus on productivity. The focus on improving productivity while reducing energy is particularly true for office environments. Here, research ranges from relatively simple $\mathrm{CO}_{2}-$ based estimation of number of people [69] to complex combination of multiple sensor types [70] , often using machine learning techniques. For single-person office spaces, presence detection through motion and door sensors can yield high accuracy and energy saving $[71,72]$ - a similar approach to that applied in single-occupant residential dorms [73]. A direct comparison of control system complexities suggests that single-occupancy offices gain significant benefit from simple presence or $\mathrm{CO}_{2}$ responsive $\mathrm{HVAC}$ control, with a smaller marginal benefit seen from more complex strategies [74]. In more diverse spaces, more complex control strategies have shown greater energy saving. For example, Wi-Fi-based smartphone tracking has been implemented to detect occupants within a larger space [75]. In a similar vein, wireless tags can be used to locate occupants in a multi-use office space, demonstrating energy saving with localised heating control [76]. In particular, spaces with highly variable use levels see a more significant improvement in energy use when accounting for real-time occupancy levels in HVAC control [77].

Response-only controls have demonstrated a potential for energy saving across all kinds of building automation. As simple response-based lighting control is already widely established, reactive control of other systems (HVAC etc.) is arguably the closest occupant-centric approach to wide scale commercial application. Reactive systems tend to follow more simple logical rules than the other approaches described below, often requiring less computing power to implement.

\subsection{Control to Individual Occupant Preference}

Some control applications benefit from input on the individual comfort level of users, catering building conditioning to each person's own preferences. Personalised lighting levels 
may be applied in a shared office space by recording lighting adjustments made by each occupant [78]. More commonly, occupant preferences are applied to thermal systems. Thermal comfort is highly subjective and thus preference data should allow much more responsive HVAC systems, greater overall comfort and improved energy efficiency. Quantification of user thermal preference has been achieved by: using personal devices to locate users and perform periodic comfort surveys [79,80]; using a range of ambient sensors to predict local comfort levels [81-83] or locate users while recording manual control adjustments [84]; estimation of thermal comfort using skin temperature as detected by IR cameras [85]; and RFID tagging and recording manual adjustments to building controls made by each user [86,87], with the inclusion of PIR for greater accuracy of location sensing [8890]. Some of the above applications are highly specific to the type of space in which they are implemented: the ambient-sensing project [84] used a range of sensors that are only applicable to learn personal preferences in a residential context with a single main occupant. By contrast, the work of Moreno-Cano et al. [88-90] is designed to be a generic platform that can learn the requirements of each user in any type of space.

Controlling building systems to individual preference is shown to create issues with comfort conflicts between individuals in multi-occupancy rooms. Further research may be required on how best to balance conflicting comfort standards in a multi-occupancy space. A potential avenue for further consideration is the distinction made between occupant groups with tracked locations/preferences and unknown occupants detected by ambient sensors: some consideration of this conflict is made in [87]. In general, application of preference-based systems has shown consistent improvement in overall comfort levels, but the overall energy saving varies depending on the building/occupancy type and on the preference of the occupant(s).

\subsection{Control to Individual Behaviours/Activity Types}

This branch of occupant-centric control is based on the assumption that a users' environmental requirements change depending on the activity taking place, or their specific behaviours. Existing studies include optimisation of localised lighting through visual detection of location and activities [91], desk lighting by combining sensor types to determine space use [64], and desk-level lighting, electrical and HVAC control based on presence and desktop computer use [92]. A domestic study has also been demonstrated, using IR cameras and presence sensors to define activity types [93].

Activity-based control has seen limited academic study, likely due to issues with the accuracy of activity detection and the availability of building systems that offer enough fine-grained control. Activity detection can also be a highly specialised task, with the effectiveness of a solution closely linked to the specific purpose, layout, and occupancy demographic of a space. To be feasibly applied, it requires either high levels of assumption about potential activities that may occur in a space, or extensive sensing that falls beyond the capability of large-scale systems at the current time.

\subsection{Control through Occupancy/Behaviour Prediction}

This control method tries to predict the occupant-based context of a space in the near future in order to pre-emptively condition the space to acceptable levels. In theory, this allows spaces to drift further away from comfort conditions while not occupied, saving energy that would have been used keeping a space to 'standby' comfort levels in a simpler control 
system. The most appropriate 'prediction horizon', or the amount of time into the future for which predictions are made, is dependent on the type of system to be controlled.

For fast-response controls, such as lighting or appliance management, the prediction horizon is typically in the order of minutes [94], or designed to predict the next action in a sequence. This form of prediction is useful for the control of power supply to household appliances, lighting etc. as in the Adaptive House [95,96] and MavHome [97,98] projects, where the environment around a user detected and recorded typical sequences of actions during use of the home. The system then attempted to automate the more common sequences.

For slower-response systems like HVAC control, predictions of occupancy must run over a longer time horizon. This requires the construction of a model of occupant behaviour from extended observation of a space, typically based on an appropriate machine learning method. The majority of such models use supervised machine learning, where the model is trained on data that is labelled with the correct outcome. Supervised models can be trained using a single batch of labelled training data: Mamidi et al. [99,100] and Howard et al. [101] developed prediction up to 90 minutes in the future using a combination of environmental sensors to define the current occupant state; while Erickson et al. [102-104] experimented with several trained methods before arriving at a system that saved $30 \%$ energy use in testing. Alternatively, models can be trained online, re-training periodically and gradually increasing accuracy during operation. For example, re-training with weighting on newer data to account for changes in building use over time [105] or continually adding new observations of presence duration to the pool of historic data used for direct similarity comparison [106] or stochastic estimation [107]. Another alternative is to build models using rules and structures that do not need to be explicitly trained with labelled data, including: inferred event sequences from ambient sensor data used to predict occupancy duration [108]; event sequences with office calendar data, weather data and a physical model of the building [109]; automatically generated daily profile matching [110], and implicit prediction of occupancy directly from thermal measurements [111]. The use of occupancy data to predict internal gains over the long term (up to 60 hours) for the purpose of optimising HVAC suggests that energy can be saved without making changes to set points when a room is vacant [112].

While many studies show the benefits of occupancy prediction in appropriate applications, there is some debate about the value of including complex predictive control over simple real-time reaction. Oldewurtel et al. tested the benefit of prediction over real-time reactive control by simulation of a single-occupant office environment [113] [114], with the conclusion that predictive control did not provide a significant benefit above reactive control. Along similar lines, Goyal et al. tested several HVAC control methods, including fixed schedules, reaction and prediction through simulation [115] and experimentation [116] for a small office space. Prediction did not show large improvement over the energy savings made by reaction only. It should be noted that in the above studies, the tested spaces are generally small and are not expected to have many occupants. Other studies have noted that spaces such as this, which can be conditioned quickly to comfort conditions, are not ideal candidates for predictive control [83] [117]. In spaces with slower response times, it has been shown that effective preconditioning of the space can yield significant energy savings [118].

\subsection{Discussion}

Due to the wide range of building types and control methods cited above, it is difficult to directly compare the energy saving made by different studies. Figure 4-2 provides a broad 
summary of the studies reviewed. It can be seen that the highest percentage energy savings were observed in predictive approaches, although variation between separate studies is high.

In research that directly compares different strategies in the same building, it appears that the greatest overall energy savings can be achieved with controls that combine real-time reactive and future-predictive approaches to optimise conditioning of a space, shown in Figure 4-1. However, there is debate on whether the benefits of predictive control justify the significant increase in complexity and computing power required over purely reactive control. In general, the value of predicting behaviours over real-time response depends on the application - most prediction models are applied to HVAC operation, as this typically has the slowest response of any building system and so can benefit the most from early warning of demand changes. By extension, factors that extend the typical response time of HVAC systems to changing demand are likely to increase the potential benefit of a predictive control approach. These factors include: spaces with larger open-plan footprints, higher thermal mass, sudden large changes in occupancy and highly intermittent space use. To the authors' knowledge, no study has yet systematically quantified the benefit of occupancy-predictive control in such circumstances, highlighting a potential gap for future research.
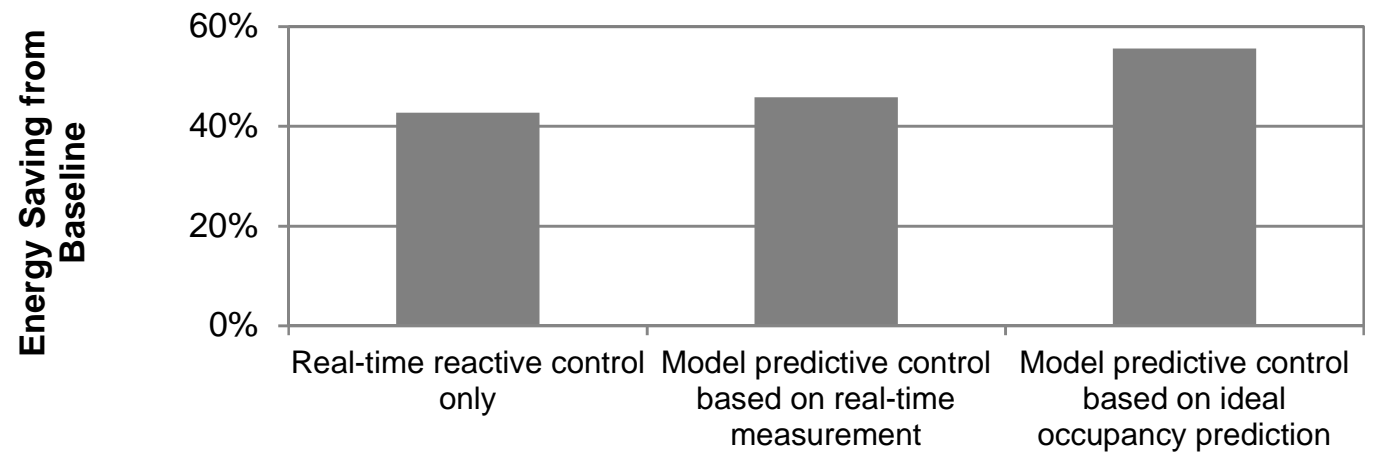

Figure 4-1 - Energy Saving Simulated in Comparison of Reactive/Predictive Strategies [115]

An attribute common to most cited studies is that the control is often tested through simulation, rather than deployment in a real building. Given that there are many identified issues with current simulation technology, there would be significant worth in testing systems by implementation in real-life buildings where possible. Practical application, however, is often limited by physical space use and hardware cost restraints. This suggests that systems making opportunistic use of existing infrastructure - through existing building systems or personal device use [75] - have the potential for wider uptake and so may be more viable for commercial application.

A further factor common to all strategies discussed in this section is the reliance on some degree of manual judgement: on what occupancy information is needed to make relevant control decisions, what control decision is appropriate at a given threshold of occupancy change, or the criteria to assess the impact of a control action. While this is not always a drawback, it highlights one of the major challenges of integrating occupant data into control systems. It is impossible to limit all sources of uncertainty when collecting data, applying control logic and assessing its effects. The assumptions and thresholds applied in practice therefore shape the capability of the control system to handle the full range of realistic human responses. For example, activity-based controls often employ manual identification of relevant categories of activity: where in-use behaviours fall outside of these pre-set bounds, a less robust system will fail to provide an appropriate control action. Where the success of a 
strategy is assessed only on its energy benefit, a decrease in occupant comfort or changing of occupant behaviour may be missed. The challenge therefore lies in making judgements that allow systems to be robust to unanticipated behaviours and outcomes.

Figure 4-2 - Summary of Studies into Occupant-Centric Building Controls

\begin{tabular}{|c|c|c|c|c|c|c|c|c|c|c|c|c|c|}
\hline \multirow[b]{2}{*}{ Authors } & \multicolumn{4}{|c|}{ Control Type } & \multicolumn{3}{|c|}{ Applied to } & \multicolumn{5}{|c|}{ Occupant Data } & \multirow[b]{2}{*}{$\begin{array}{c}\text { Reported } \\
\text { Energy Saving } \\
\text { vs Baseline }\end{array}$} \\
\hline & 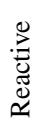 & 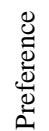 & 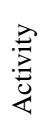 & 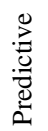 & 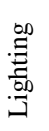 & 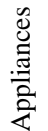 & 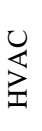 & 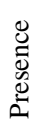 & 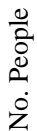 & 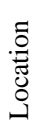 & हैं & : & \\
\hline Garg \& Bansal [62] & 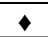 & & & & $\bullet$ & & & 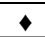 & & & & & $25 \%$ \\
\hline Labeodan et al. [63] & 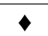 & & & & $\bullet$ & & & $\bullet$ & & $\downarrow$ & & & $24 \%$ \\
\hline Park et al. [66] & 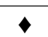 & & & & & $\bullet$ & & $\bullet$ & & & & & $\leq 21 \%$ \\
\hline Harris \& Cahill [67] & 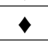 & & & & & 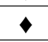 & & & & 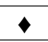 & & & Not reported \\
\hline Batra et al. [73] & 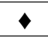 & & & & & & $\bullet$ & 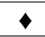 & & & & & Not reported \\
\hline Sun et al. [69] & 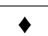 & & & & & & $\bullet$ & & $\bullet$ & & & & $\leq 56 \%$ \\
\hline Agarwal et al. [71] & $\bullet$ & & & & & & $\bullet$ & $\bullet$ & & & & & $10-15 \%$ \\
\hline Agarwal et al. [75] & 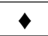 & & & & & & $\bullet$ & & & 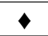 & & & $17.8 \%$ \\
\hline Zeiler et al. [76] & 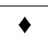 & & & & & & 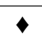 & & & - & & & $30-45 \%$ \\
\hline Rosiek and Batlles [77] & 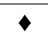 & & & & & & $\bullet$ & 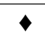 & & & & & $42 \%$ \\
\hline Gruber et al. [74] & 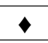 & & & & & & $\bullet$ & 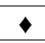 & & & & & $6-39 \%$ \\
\hline Yang et al. [70] & 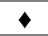 & & & & & & $\bullet$ & & 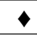 & & & & $18-20 \%$ \\
\hline Singhvi et al. [78] & & - & & & $\bullet$ & & & & & $\bullet$ & & & Not reported \\
\hline Zhao et al. [81] & & $\bullet$ & & & & & $\bullet$ & & & & 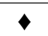 & & $44 \% *$ \\
\hline Kolokotsa et al. [82] & & 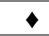 & & & $\bullet$ & & $\bullet$ & $\bullet$ & & & $\bullet$ & & Not reported \\
\hline Gao \& Keshav [83] & & $\bullet$ & & & & & $\bullet$ & 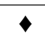 & $\bullet$ & & 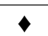 & & Not reported \\
\hline Jazizadeh et al. [80] & & $\bullet$ & & & & & $\bullet$ & $\bullet$ & & & 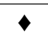 & & $26-39 \%$ \\
\hline Yong et al. [79] & & $\bullet$ & & & & & $\bullet$ & 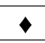 & & & $\bullet$ & & Not reported \\
\hline Hagras et al. [84] & & $\bullet$ & & & $\bullet$ & & $\bullet$ & - & & & & & Not reported \\
\hline Chen et al. [86] & & $\bullet$ & & & $\bullet$ & & $\bullet$ & & & $\bullet$ & & & Not reported \\
\hline Moreno-Cano et al. [88-90] & & $\bullet$ & & & $\bullet$ & 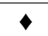 & $\bullet$ & & & 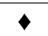 & & & $20 \%$ \\
\hline Yeh et al. [87] & & 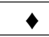 & & & $\bullet$ & $\bullet$ & $\bullet$ & & & 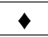 & & & $16.5-46.9 \%$ \\
\hline Vissers and Zeiler [85] & & $\bullet$ & & & & & $\bullet$ & $\bullet$ & & 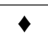 & 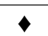 & & $<17 \%$ \\
\hline Lee et al. [91] & & & 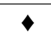 & & $\bullet$ & & & & & 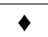 & & 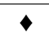 & Not reported \\
\hline Xu et al. [64] & & & 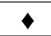 & & $\bullet$ & & & 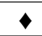 & & & & $\bullet$ & $\leq 34 \%$ \\
\hline Milenkovic \& Amft [92] & & & 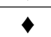 & & $\bullet$ & 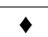 & & - & & & & 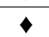 & $21.9 \%$ \\
\hline Pallotta et al. [93] & & & 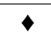 & & & & $\bullet$ & $\bullet$ & & & & $\rightarrow$ & Not reported \\
\hline Harle \& Hopper [94] & & & & - & $\bullet$ & $\bullet$ & & & & 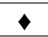 & & & $50 \%$ \\
\hline Mozer $[95,96]$ & & & & - & $\bullet$ & & & & & & & $\bullet$ & Not reported \\
\hline Cook et al. [97] & & & & 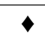 & $\bullet$ & $\bullet$ & & $\bullet$ & & & & 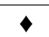 & Not reported \\
\hline Mamidi et al. $[99,100]$ & & & & 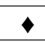 & & & $\bullet$ & & $\bullet$ & & & & Not reported \\
\hline Howard \& Hoff [101] & & & & 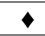 & & & & $\bullet$ & & & & & Not reported \\
\hline Dong et al. $[108,109]$ & & & & $\bullet$ & & & $\bullet$ & & 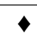 & & & & $18-30 \%$ \\
\hline Dobbs and Hencey [105] & & & & $\bullet$ & & & $\bullet$ & 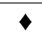 & & & & & $8 \%$ \\
\hline Peng et al. [106] & & & & $\bullet$ & & & $\bullet$ & - & & & & & $20.3 \%$ \\
\hline Gunay et al. [107] & & & & - & & & $\bullet$ & $\bullet$ & & & & & $10-15 \%$ \\
\hline Aswani et al. [111] & & & & 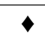 & & & $\bullet$ & & $\bullet$ & & & & $30-70 \%$ \\
\hline Barbato et al. [110] & & & & 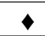 & & & $\bullet$ & $\bullet$ & & & & & $\leq 28 \%$ \\
\hline Erickson et al. [102-104] & & & & $\bullet$ & & & $\bullet$ & & $\bullet$ & & & & $\leq 42 \%$ \\
\hline Zhang et al. [112] & & & & $\bullet$ & & & $\bullet$ & & 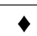 & & & & Not reported \\
\hline Oldewurtel et al. [113] [114] & & & & $\bullet$ & & & $\bullet$ & $\bullet$ & & & & & $\leq 34 \% *$ \\
\hline Goyal et al. $[115,116]$ & & & & 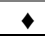 & & & 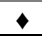 & & 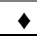 & & & & $\leq 56-61 \% *$ \\
\hline
\end{tabular}

*Simulated result of ideal prediction

\section{Conclusions}

The observable gap between designed and actual energy performance across a range of building types highlights the need for more complex and responsive building controls, catered to real-time measurable building occupant energy demand. A range of studies have confirmed that occupants significantly affect the energy requirements of a building through varying use patterns and energy-related behaviours. However, the majority of current building control systems are not suited to the task of occupant-responsive control. 
Relatively simple schedule-based systems remain the most common commercial building controls. In such systems, the building conditions are maintained to a steady level throughout the scheduled period, with no regard to the actual use of the building by occupants. Control sensing and actuation hardware is often not localised enough to cater to the needs of individuals or occupants of a particular sub-zone within a larger building. However, trends in the availability of increasingly affordable, easily installed wireless technologies and industry interest in more comprehensive control software suites suggest that more complex, responsive systems will become more commonplace in the future. Recent trends in the availability of home automation suites show an increased responsiveness to occupancy patterns, allowing a centralised control hub to integrate with smartphone location services, remote access and self-learning algorithms for automated scheduling. It can be expected that such occupant-centred technologies will also see wider integration into complex commercial controls in the future, although the increased complexity of larger and more diverse building populations presents a range of further barriers to commercial uptake.

The concept of 'occupant data' can cover a wide range of detail and disaggregation levels. This complicates the study of how to optimise data collection methods, as often the qualities of occupancy data required depend entirely on the intended application. Studies were divided into three broad categories: the detection of occupant presence/numbers, locationing and the detection of specific activities. While a wide range of sensor technologies were tested across different works, a general trend was observed towards a trade-off between the level of detail in the data collected and the expected accuracy of results. Studies aiming to parse presence data within smaller spaces typically found simpler systems of motion sensors or $\mathrm{CO}_{2}$ concentration to be sufficient, while full 3D location or activity detection required more computationally intensive processes, often involving the combination of multiple sensor types in trained models. The success of technologies relying on physical properties of the observed space were found to vary across studies, suggesting that generic application of the same sensing systems across diverse building types may not be feasible. Most importantly, perhaps, is the data collection must be robust in order to provide benefit: the BEMS value of occupant data is provided in parsing information that is actionable for building controls. For example, if an occupant system has no way to detect a sub-section of building occupants whether occupants standing outside motion sensor range or building visitors who do not carry location tags - poor control choices could be made when this sub-section is present and not detected. The combination of multiple approaches can help to decrease these robustness issues.

In the application of detection systems to building controls, the range of applications can be broadly described by: real-time response, occupant preference, activity response, and future prediction. Academic trials of these systems show great variability depending on application, but generally the more complex systems such as prediction can achieve the greatest potential energy saving, at the cost of greater computational requirements. This appeared to be true for slower response systems in particular, although it was noted that the breadth of studies did not directly account for these factors. Given how application-dependent energy savings are across the range of studies presented in this work, it is proposed that a framework for more systematic treatment and categorisation of applications would allow for a richer crossassessment of the benefits and drawbacks of different occupant-centred control strategies. In order for this to be effective, it would also be necessary for a wider range of strategies to be tested in live buildings rather than through simulation. The opportunistic use of existing data collection hardware, in particular the increasing amount of data collected through widespread smartphone use across many populations, may allow for wider application of occupant- 
centred testing. In order to move forward in the field of occupant-centred energy management, a further major challenge is the robustness of design strategies to unanticipated occupant behaviours. It is impossible to limit all sources of uncertainty when collecting data, applying control logic and assessing its effects. The assumptions and thresholds applied in practice therefore shape the capability of the control system to handle the full range of realistic human responses.

It is clear that the field of Building Energy Management/Control is evolving, and that increased use of intelligence in control systems has become viable as the cost of such technologies decreases. As technologies emerge to allow for more accurate and detailed occupant data collection, control systems will continue to develop. The authors are developing works on the application of smart device Wi-Fi and Bluetooth detection to reactive/predictive office energy management/control.

\section{Acknowledgements}

This work was supported by the EPSRC and Laing O'Rourke as part of a $\mathrm{PhD}$ programme at the University of Nottingham, UK.

\section{References}

[1] Whiffen TR, Naylor S, Hill J, Smith L, Callan PA, Gillott M, et al. A concept review of power line communication in building energy management systems for the small to medium sized non-domestic built environment. Renew Sustain Energy Rev 2016.

[2] Menezes AC, Cripps A, Bouchlaghem D, Buswell R. Predicted vs. actual energy performance of non-domestic buildings: Using post-occupancy evaluation data to reduce the performance gap. Appl Energy 2012;97:355-64. doi:10.1016/j.apenergy.2011.11.075.

[3] CarbonBuzz. Summary of Audits Performed on CarbonBuzz by the UCL Energy Institute 2013. http://www.carbonbuzz.org/downloads/PerformanceGap.pdf (accessed May 6, 2014).

[4] Eguaras-Martínez M, Vidaurre-Arbizu M, Martín-Gómez C. Simulation and evaluation of Building Information Modeling in a real pilot site. Appl Energy 2014;114:475-84. doi:10.1016/j.apenergy.2013.09.047.

[5] Clevenger CM, Haymaker J. The impact of the building occupant on energy modeling simulations. Jt. Int. Conf. Comput. Decis. Mak. Civ. Build. Eng. Montr. Can., Citeseer; 2006, p. 1-10.

[6] Yu Z, Fung BCM, Haghighat F, Yoshino H, Morofsky E. A systematic procedure to study the influence of occupant behavior on building energy consumption. Energy Build 2011;43:1409-17. doi:10.1016/j.enbuild.2011.02.002.

[7] Yohanis YG, Mondol JD, Wright A, Norton B. Real-life energy use in the UK: How occupancy and dwelling characteristics affect domestic electricity use. Energy Build 2008;40:1053-9. doi:10.1016/j.enbuild.2007.09.001.

[8] Martani C, Lee D, Robinson P, Britter R, Ratti C. ENERNET: Studying the dynamic relationship between building occupancy and energy consumption. Energy Build 2012;47:584-91. doi:10.1016/j.enbuild.2011.12.037.

[9] Masoso OT, Grobler LJ. The dark side of occupants' behaviour on building energy use. Energy Build 2010;42:173-7. doi:10.1016/j.enbuild.2009.08.009.

[10] Lowe R, Oreszczyn T. Regulatory standards and barriers to improved performance for housing. Energy Policy 2008;36:4475-81. doi:10.1016/j.enpol.2008.09.024. 
[11] SEAI - Building Energy Management Systems (BEMS) n.d. http://www.seai.ie/Your_Business/Technology/Buildings/Building_Energy_Manageme nt_Systems_BEMS_.html (accessed January 20, 2014).

[12] Shaikh PH, Nor NBM, Nallagownden P, Elamvazuthi I, Ibrahim T. A review on optimized control systems for building energy and comfort management of smart sustainable buildings. Renew Sustain Energy Rev 2014;34:409-29. doi:10.1016/j.rser.2014.03.027.

[13] Carbon Trust. Building controls: Realising savings through the use of controls. 2007.

[14] Escrivá-Escrivá G, Álvarez-Bel C, Peñalvo-López E. New indices to assess building energy efficiency at the use stage. Energy Build 2011;43:476-84. doi:10.1016/j.enbuild.2010.10.012.

[15] Fox JP, Wheelock C. Executive Summary: Building Energy Management Systems Enabling Systems for Energy Efficiency, Demand Response, Energy Management, and Facility Automation in Commercial Buildings. Pike Research; 2010.

[16] Best Home Automation UK 2016 - A Detailed Comparison n.d. http://www.appcessories.co.uk/best-home-automation-uk-system/ (accessed March 7, 2016).

[17] Hive Thermostat \& Heating Control App | Hive Active Heating n.d. https://www.hivehome.com/hive-active-heating (accessed October 30, 2015).

[18] Meet the Nest Thermostat. Nest n.d. https://nest.com/uk/thermostat/meet-nestthermostat/ (accessed October 30, 2015).

[19] Heat Genius Products and Services: Heating App, Smart Thermostats n.d. https://www.heatgenius.co.uk/products/ (accessed October 30, 2015).

[20] For Heating \& Air Conditioning - Intelligent Climate Control. Tado ${ }^{\circ}$ n.d. https://www.tado.com/gb (accessed October 30, 2015).

[21] evohome - Honeywell UK Heating Controls n.d. http://www.honeywelluk.com/products/Underfloor-Heating/evohome-Main/ (accessed October 30, 2015).

[22] Martin J. Nest's latest thermostat can control your hot water as well as your heating. Tech Advis 2017. http://www.techadvisor.co.uk/review/smart-thermostats/nestthermostat-review-3rd-gen-3543915/ (accessed September 24, 2017).

[23] Naghiyev E, Gillott M, Wilson R. Three unobtrusive domestic occupancy measurement technologies under qualitative review. Energy Build 2014;69:507-14. doi:10.1016/j.enbuild.2013.11.033.

[24] Hailemariam E, Goldstein R, Attar R, Khan A. Real-time occupancy detection using decision trees with multiple sensor types. Proc. 2011 Symp. Simul. Archit. Urban Des., 2011, p. 141-148.

[25] Yu T. Modeling Occupancy Behavior for Energy Efficiency and Occupants Comfort Management in Intelligent Buildings, IEEE; 2010, p. 726-31. doi:10.1109/ICMLA.2010.111.

[26] Meyn S, Surana A, Lin Y, Oggianu SM, Narayanan S, Frewen TA. A sensor-utilitynetwork method for estimation of occupancy distribution in buildings. Decis. Control 2009 Held Jointly 2009 28th Chin. Control Conf. CDCCCC 2009 Proc. 48th IEEE Conf. On, 2009, p. 1494-1500.

[27] İçoğlu O, Mahdavi A. VIOLAS: A vision-based sensing system for sentient building models. Autom Constr 2007;16:685-712. doi:10.1016/j.autcon.2006.11.007.

[28] Ebadat A, Bottegal G, Varagnolo D, Wahlberg B, Johansson KH. Estimation of building occupancy levels through environmental signals deconvolution, ACM Press; 2013, p. 18. doi:10.1145/2528282.2528290. 
[29] Dong B, Andrews B, Lam KP, Höynck M, Zhang R, Chiou Y-S, et al. An information technology enabled sustainability test-bed (ITEST) for occupancy detection through an environmental sensing network. Energy Build 2010;42:1038-46.

doi:10.1016/j.enbuild.2010.01.016.

[30] Lam KP, Hoynck M, Zhang R, Andrews B, Chiou Y-S, Dong B, et al. Informationtheoretic environmental features selection for occupancy detection in open offices. Elev. Int. IBPSA Conf. Ed. PA Strachan NJ Kelly M Kummert, 2009, p. 1460-1467.

[31] Yang Z, Li N, Becerik-Gerber B, Orosz M. A multi-sensor based occupancy estimation model for supporting demand driven HVAC operations. Proc. 2012 Symp. Simul. Archit. Urban Des., 2012, p. 2.

[32] Ekwevugbe T, Brown N, Pakka V, Fan D. Improved occupancy monitoring in nondomestic buildings. Sustain Cities Soc 2017;30:97-107. doi:10.1016/j.scs.2017.01.003.

[33] Curran K, Furey E, Lunney T, Santos J, Woods D, Mc Caughey A. An Evaluation of Indoor Location Determination Technologies. J Locat Based Serv 2011;5:61-78.

[34] Misra A, Das SK. Location Estimation (Determination and Prediction) Techniques in Smart Environments. Smart Environ. Technol. Protoc. Appl., Hoboken, NJ, USA: John Wiley \& Sons, Incorporated; 2004, p. 193-228.

[35] Li N, Calis G, Becerik-Gerber B. Measuring and monitoring occupancy with an RFID based system for demand-driven HVAC operations. Autom Constr 2012;24:89-99. doi:10.1016/j.autcon.2012.02.013.

[36] Zhen Z-N, Jia Q-S, Song C, Guan X. An indoor localization algorithm for lighting control using RFID. Energy 2030 Conf. 2008 ENERGY 2008 IEEE, 2008, p. 1-6.

[37] Spataru C, Gillott M. The use of intelligent systems for monitoring energy use and occupancy in existing homes. Sustain. Energy Build., Springer; 2011, p. 247-256.

[38] Spataru C, Gillott M, Hall MR. Domestic energy and occupancy: a novel postoccupancy evaluation study. Int J Low-Carbon Technol 2010;5:148-57. doi:10.1093/ijlct/ctq020.

[39] Shipman R, Gillott M. A Study of the Use of Wireless Behavior Systems to Encourage Energy Efficiency in Domestic Properties, Hong Kong: 2013.

[40] Dodier RH, Henze GP, Tiller DK, Guo X. Building occupancy detection through sensor belief networks. Energy Build 2006;38:1033-43. doi:10.1016/j.enbuild.2005.12.001.

[41] Hay S, Harle R. Bluetooth tracking without discoverability. Locat. Context Aware., Springer; 2009, p. 120-137.

[42] Zhao Y, Zeiler W, Boxem G, Labeodan T. Virtual occupancy sensors for real-time occupancy information in buildings. Build Environ 2015;93:9-20. doi:10.1016/j.buildenv.2015.06.019.

[43] Jun J, Cheng L, Sun J, Gu Y, Zhu T, He T. Improving Indoor Localization with Social Interactions. Proc. 10th ACM Conf. Embed. Netw. Sens. Syst., New York, NY, USA: ACM; 2012, p. 323-324. doi:10.1145/2426656.2426689.

[44] Lee D, Oh S. Understanding human-place interaction from tracking and identification of many users. Cyber-Phys. Syst. Netw. Appl. CPSNA 2013 IEEE 1st Int. Conf. On, 2013, p. 112-115.

[45] Bruckner D, Velik R. Behavior Learning in Dwelling Environments With Hidden Markov Models. IEEE Trans Ind Electron 2010;57:3653-60. doi:10.1109/TIE.2010.2045992.

[46] Zhao ZB, Xu WS, Cheng DZ. User behavior detection framework based on NBP for energy efficiency. Autom Constr 2012;26:69-76. doi:10.1016/j.autcon.2012.04.001.

[47] Nguyen TA, Aiello M. Beyond Indoor Presence Monitoring with Simple Sensors. PECCS, 2012, p. 5-14. 
[48] Sebbak F, Chibani A, Amirat Y, Mokhtari A, Benhammadi F. An evidential fusion approach for activity recognition in ambient intelligence environments. Robot Auton Syst 2013;61:1235-45. doi:10.1016/j.robot.2013.05.010.

[49] Ortega JLG, Han L, Whittacker N, Bowring N. A machine-learning based approach to model user occupancy and activity patterns for energy saving in buildings. Sci. Inf. Conf. SAI 2015, 2015, p. 474-82. doi:10.1109/SAI.2015.7237185.

[50] Philipose M, Fishkin KP, Perkowitz M, Patterson DJ, Fox D, Kautz H, et al. Inferring activities from interactions with objects. IEEE Pervasive Comput 2004;3:50-7. doi:10.1109/MPRV.2004.7.

[51] Gonzalez LIL, Troost M, Amft O. Using a Thermopile Matrix Sensor to Recognize Energy-related Activities in Offices. Procedia Comput Sci 2013;19:678-85. doi:10.1016/j.procs.2013.06.090.

[52] Fernandez-Luque FJ, Martínez F, Domènech G, Zapata J, Ruiz R. EMFi-based lowpower occupancy sensor. Sens Actuators Phys 2013;191:78-88. doi:10.1016/j.sna.2012.11.027.

[53] Benezeth Y, Laurent H, Emile B, Rosenberger C. Towards a sensor for detecting human presence and characterizing activity. Energy Build 2011;43:305-14. doi:10.1016/j.enbuild.2010.09.014.

[54] Kazmi AH, O'grady MJ, Delaney DT, Ruzzelli AG, O'hare GMP. A Review of Wireless-Sensor-Network-Enabled Building Energy Management Systems. ACM Trans Sen Netw 2014;10:66:1-66:43. doi:10.1145/2532644.

[55] Deloitte. State of the smart: Consumer and business usage patterns, Global Mobile Consumer Survey 2017: The UK cut. 2017.

[56] Ekwevugbe T, Brown N, Fan D. Using indoor climatic measurements for occupancy monitoring 2012.

[57] Mahmoud S, Lotfi A, Langensiepen C. Behavioural pattern identification and prediction in intelligent environments. Appl Soft Comput 2013;13:1813-22. doi:10.1016/j.asoc.2012.12.012.

[58] Chen D, Barker S, Subbaswamy A, Irwin D, Shenoy P. Non-Intrusive Occupancy Monitoring using Smart Meters, ACM Press; 2013, p. 1-8. doi:10.1145/2528282.2528294.

[59] Georgescu M, Mezic I. Estimating Occupancy States from Building Temperature Data using Wavelet Analysis. BS2013, Le Bourget Du Lac, France: 2013.

[60] Patel SN, Reynolds MS, Abowd GD. Detecting Human Movement by Differential Air Pressure Sensing in HVAC System Ductwork: An Exploration in Infrastructure Mediated Sensing. In: Indulska J, Patterson DJ, Rodden T, Ott M, editors. Pervasive Comput., Springer Berlin Heidelberg; 2008, p. 1-18.

[61] Nguyen TA, Aiello M. Energy intelligent buildings based on user activity: A survey. Energy Build 2013;56:244-57. doi:10.1016/j.enbuild.2012.09.005.

[62] Garg V, Bansal NK. Smart occupancy sensors to reduce energy consumption. Energy Build 2000;32:81-87.

[63] Labeodan T, De Bakker C, Rosemann A, Zeiler W. On the application of wireless sensors and actuators network in existing buildings for occupancy detection and occupancy-driven lighting control. Energy Build 2016;127:75-83. doi:10.1016/j.enbuild.2016.05.077.

[64] Xu Y, Stojanovic N, Stojanovic L, Anicic D, Studer R. An approach for more efficient energy consumption based on real-time situational awareness. Semanic Web Res. Appl., Springer; 2011, p. 270-284.

[65] energyEGG n.d. http://energy-egg.com/our-story/ (accessed June 5, 2014). 
[66] Park S, Choi M, Kang B, Park S. Design and Implementation of Smart Energy Management System for Reducing Power Consumption Using ZigBee Wireless Communication Module. Procedia Comput Sci 2013;19:662-8. doi:10.1016/j.procs.2013.06.088.

[67] Harris C, Cahill V. Exploiting user behaviour for context-aware power management. Wirel. Mob. Comput. Netw. Commun. 2005WiMob2005 IEEE Int. Conf. On, vol. 4, 2005, p. 122-130.

[68] Meyer S, Rakotonirainy A. A survey of research on context-aware homes. Proc. Australas. Inf. Secur. Workshop Conf. ACSW Front. 2003-Vol. 21, 2003, p. 159-168.

[69] Sun Z, Wang S, Ma Z. In-situ implementation and validation of a CO2-based adaptive demand-controlled ventilation strategy in a multi-zone office building. Build Environ 2011;46:124-33. doi:10.1016/j.buildenv.2010.07.008.

[70] Yang Z, Li N, Becerik-Gerber B, Orosz M. A systematic approach to occupancy modeling in ambient sensor-rich buildings. Simulation 2013;90:960-77. doi:10.1177/0037549713489918.

[71] Agarwal Y, Balaji B, Gupta R, Lyles J, Wei M, Weng T. Occupancy-driven energy management for smart building automation. Proc. 2nd ACM Workshop Embed. Sens. Syst. Energy-Effic. Build., 2010, p. 1-6.

[72] Agarwal Y, Balaji B, Dutta S, Gupta RK, Weng T. Duty-cycling buildings aggressively: The next frontier in HVAC control. 2011 10th Int. Conf. Inf. Process. Sens. Netw. IPSN, 2011, p. 246-57.

[73] Batra N, Arjunan P, Singh A, Singh P. Experiences with Occupancy Based Building Management Systems 2013.

[74] Gruber M, Trüschel A, Dalenbäck J-O. Alternative strategies for supply air temperature control in office buildings. Energy Build n.d. doi:10.1016/j.enbuild.2014.06.056.

[75] Balaji B, Xu J, Nwokafor A, Gupta R, Agarwal Y. Sentinel: occupancy based HVAC actuation using existing WiFi infrastructure within commercial buildings. Proc. 11th ACM Conf. Embed. Netwroked Sens. Syst., 2013.

[76] Zeiler W, Boxem G, Maaijen R. Wireless Sensor Technology to Optimize the Occupant's Dynamic Demand Pattern within the Building 2012.

[77] Rosiek S, Batlles FJ. Reducing a solar-assisted air-conditioning system's energy consumption by applying real-time occupancy sensors and chilled water storage tanks throughout the summer: A case study. Energy Convers Manag 2013;76:1029-42. doi:10.1016/j.enconman.2013.08.060.

[78] Singhvi V, Krause A, Guestrin C, Garrett Jr JH, Matthews HS. Intelligent light control using sensor networks. Proc. 3rd Int. Conf. Embed. Networked Sens. Syst., 2005, p. 218-229.

[79] Yong CY, Qiao B, Wilson DJ, Wu M, Clements-Croome D, Liu K, et al. Co-ordinated management of intelligent pervasive spaces. Ind. Inform. 20075 th IEEE Int. Conf. On, vol. 1, 2007, p. 529-534.

[80] Jazizadeh F, Ghahramani A, Becerik-Gerber B, Kichkaylo T, Orosz M. User-led decentralized thermal comfort driven HVAC operations for improved efficiency in office buildings. Energy Build 2014;70:398-410. doi:10.1016/j.enbuild.2013.11.066.

[81] Zhao J, Lam KP, Ydstie BE, Loftness V. Occupant-oriented mixed-mode EnergyPlus predictive control simulation. Energy Build n.d. doi:10.1016/j.enbuild.2015.09.027.

[82] Kolokotsa D, Saridakis G, Pouliezos A, Stavrakakis GS. Design and installation of an advanced EIB ${ }^{\mathrm{TM}}$ fuzzy indoor comfort controller using Matlab ${ }^{\mathrm{TM}}$. Energy Build 2006;38:1084-92. doi:10.1016/j.enbuild.2005.12.007.

[83] Gao PX, Keshav S. SPOT: a smart personalized office thermal control system. Proc. Fourth Int. Conf. Future Energy Syst., 2013, p. 237-246. 
[84] Hagras H, Callaghan V, Colley M, Clarke G, Pounds-Cornish A, Duman H. Creating an ambient-intelligence environment using embedded agents. Intell Syst IEEE 2004;19:1220.

[85] Vissers D, Zeiler W. The User as Sensor to Reach for Optimal Individual Comfort and Reduced Energy Consumption. Oppor. Limits Needs Environ. Responsible Archit., Lima, Perú: 2012.

[86] Chen H, Chou P, Duri S, Lei H, Reason J. The Design and Implementation of a Smart Building Control System, IEEE; 2009, p. 255-62. doi:10.1109/ICEBE.2009.42.

[87] Yeh L-W, Wang Y-C, Tseng Y-C. iPower: an energy conservation system for intelligent buildings by wireless sensor networks. Int J Sens Netw 2009;5:1-10. doi:10.1504/IJSNet.2009.023311.

[88] Moreno MV, Zamora MA, Skarmeta AF. User-centric smart buildings for energy sustainable smart cities. Trans Emerg Telecommun Technol 2013:n/a-n/a. doi:10.1002/ett.2771.

[89] Moreno-Cano MV, Santa J, Zamora MA, Gómez AFS. Context-Aware Energy Efficiency in Smart Buildings. Ubiquitous Comput. Ambient Intell. Context-Aware. Context-Driven Interact., Springer; 2013, p. 1-8.

[90] Moreno-Cano MV, Zamora-Izquierdo MA, Santa J, Skarmeta AF. An Indoor Localization System Based on Artificial Neural Networks and Particle Filters Applied to Intelligent Buildings. Neurocomput 2013;122:116-125. doi:10.1016/j.neucom.2013.01.045.

[91] Lee H, Wu C, Aghajan H. Vision-based user-centric light control for smart environments. Pervasive Mob Comput 2011;7:223-40. doi:10.1016/j.pmcj.2010.08.003.

[92] Milenkovic M, Amft O. An opportunistic activity-sensing approach to save energy in office buildings. Proc. Fourth Int. Conf. Future Energy Syst., 2013, p. 247-258.

[93] Pallotta V, Bruegger P, Hirsbrunner B. Smart heating systems: Optimizing heating systems by kinetic-awareness. Third Int. Conf. Digit. Inf. Manag. 2008 ICDIM 2008, 2008, p. 887-92. doi:10.1109/ICDIM.2008.4746833.

[94] Harle RK, Hopper A. The potential for location-aware power management. Proc. 10th Int. Conf. Ubiquitous Comput., 2008, p. 302-311.

[95] The adaptive house n.d. http://www.cs.colorado.edu/ mozer/index.php?dir=/Research/Projects/Adaptive\%20hou se/ (accessed January 14, 2014).

[96] Mozer MC. Lessons from an adaptive home. Smart Environ. Technol. Protoc. Appl., Hoboken, NJ, USA: John Wiley \& Sons, Incorporated; 2004, p. 273-98.

[97] Cook DJ, Youngblood M, Heierman, E.O. I, Gopalratnam K, Rao S, Litvin A, et al. MavHome: an agent-based smart home. Proc. First IEEE Int. Conf. Pervasive Comput. Commun. 2003 PerCom 2003, 2003, p. 521-4. doi:10.1109/PERCOM.2003.1192783.

[98] Cook DJ, Youngblood GM, Jain G. Algorithms for smart spaces. Eng Handb Smart Technol Aging Dissablity Independence Wiley 2008:783-800.

[99] Mamidi S, Chang Y-H, Maheswaran R. Smart Sensing, Estimation, and Prediction for Efficient Building Energy Management. Multi-Agent Smart Comput. Workshop, 2011.

[100] Mamidi S, Chang Y-H, Maheswaran R. Improving Building Energy Efficiency with a Network of Sensing, Learning and Prediction Agents. Proc. 11th Int. Conf. Auton. Agents Multiagent Syst. - Vol. 1, Richland, SC: International Foundation for Autonomous Agents and Multiagent Systems; 2012, p. 45-52.

[101] Howard J, Hoff W. Forecasting building occupancy using sensor network data. Proc. 2nd Int. Workshop Big Data Streams Heterog. Source Min. Algorithms Syst. Program. Models Appl., 2013, p. 87-94. 
[102] Erickson VL, Lin Y, Kamthe A, Brahme R, Surana A, Cerpa AE, et al. Energy efficient building environment control strategies using real-time occupancy measurements. Proc. First ACM Workshop Embed. Sens. Syst. Energy-Effic. Build., 2009, p. 19-24.

[103] Erickson VL, Carreira-Perpinan MA, Cerpa AE. OBSERVE: Occupancy-based system for efficient reduction of HVAC energy. Inf. Process. Sens. Netw. IPSN 2011 10th Int. Conf. On, 2011, p. 258-269.

[104] Erickson VL, Achleitner S, Cerpa AE. POEM: power-efficient occupancy-based energy management system. Proc. 12th Int. Conf. Inf. Process. Sens. Netw., 2013, p. 203-216.

[105] Dobbs JR, Hencey BM. Model Predictive HVAC Control with Online Occupancy Model. ArXiv14034662 Cs 2014.

[106] Peng Y, Rysanek A, Nagy Z, Schlüter A. Occupancy learning-based demand-driven cooling control for office spaces. Build Environ 2017;122:145-60. doi:10.1016/j.buildenv.2017.06.010.

[107] Burak Gunay H, O’Brien W, Beausoleil-Morrison I. Development of an occupancy learning algorithm for terminal heating and cooling units. Build Environ 2015;93, Part 2:71-85. doi:10.1016/j.buildenv.2015.06.009.

[108] Dong B, Andrews B. Sensor-based occupancy behavioral pattern recognition for energy and comfort management in intelligent buildings. Proc Int IBPSA Conf, 2009.

[109] Dong B, Lam KP. A real-time model predictive control for building heating and cooling systems based on the occupancy behavior pattern detection and local weather forecasting. Build Simul 2013;7:89-106. doi:10.1007/s12273-013-0142-7.

[110] Barbato A, Borsani L, Capone A, Melzi S. Home energy saving through a user profiling system based on wireless sensors. Proc. First ACM Workshop Embed. Sens. Syst. Energy-Effic. Build., 2009, p. 49-54.

[111] Aswani A, Master N, Taneja J, Krioukov A, Culler D, Tomlin C. Energy-efficient building hvac control using hybrid system lbmpc. ArXiv Prepr ArXiv12044717 2012.

[112] Zhang X, Schildbach G, Sturzenegger D, Morari M. Scenario-based MPC for energyefficient building climate control under weather and occupancy uncertainty. Control Conf. ECC 2013 Eur., 2013, p. 1029-1034.

[113] Oldewurtel F, Sturzenegger D, Morari M. Importance of occupancy information for building climate control. Appl Energy 2013;101:521-32. doi:10.1016/j.apenergy.2012.06.014.

[114] Sturzenegger D, Oldewurtel F, Morari M. Importance of Long-Term Occupancy Information-A Validation with Real Occupancy Data. Clima-RHEVA World Congr., 2013.

[115] Goyal S, Ingley HA, Barooah P. Occupancy-based zone-climate control for energyefficient buildings: Complexity vs. performance. Appl Energy 2013;106:209-21. doi:10.1016/j.apenergy.2013.01.039.

[116] Goyal S, Barooah P, Middelkoop T. Experimental study of occupancy-based control of HVAC zones 2014.

[117] Gruber M, Trüschel A, Dalenbäck J-O. Model-based controllers for indoor climate control in office buildings - Complexity and performance evaluation. Energy Build 2014;68:213-222.

[118] Lu J, Sookoor T, Srinivasan V, Gao G, Holben B, Stankovic J, et al. The smart thermostat: using occupancy sensors to save energy in homes. Proc. 8th ACM Conf. Embed. Networked Sens. Syst., 2010, p. 211-224. 